\section{KONFLIKTE LÖSEN}

Liebe Leserin, lieber Leser,

Gehören Konflikte im Beruf zum Alltag? Aber ja, und auf lange Sicht bringt es sicher keinen Gewinn, wenn man die tagtäglichen Konflikte einfach wegschiebt, sie verdeckt, statt sie in einer angemessenen Form auszutragen. Fragwürdig ist aber auch eine kurzfristig gespielte Harmonie, denn die Atmosphäre ist vergiftet, selbst wenn man sich dessen nicht so recht bewusst ist. Die heute notwendige Teamarbeit ist in dieser Hinsicht in allen Arbeitsbereichen eine Herausforderung, wie sie auch vielseitige Chancen zur Konfliktlösung bietet.

Wenn schon Konflikte zum beruflichen Umfeld dazugehören, halten sie manche doch für negativ und zerstörerisch. Unbestritten gibt es diese Seite des Konflikts; Gefahr und Risiko sind nicht zu leugnen. Aber gehört nicht zu jedem Risiko auch eine Chance!? Nämlich über den Konflikt und die Phase der Spannung zu einem neuen Einverständnis zu finden. Allerdings fällt einem diese Chance nicht in den Schoß. Man kann aber eine Menge dazu tun, sie zu nutzen.

Lässt sich denn die Bewältigung von Konflikten lernen? Ich denke schon; es kann sogar Spaß machen, an Konflikte heranzugehen. Eine Möglichkeit wäre die Form des Streits. Ja, obwohl das Wort „Streit“ für viele einen negativen Beigeschmack hat. Wenn man darunter eine Auseinandersetzung versteht, dann ist Streit jedoch weder gut noch böse. Das Fehlen von Streit bedeutet ja noch lange nicht, dass eine Beziehung gut funktioniert.

Chefredakteur und Herausgeber
Kommt man also ums Streiten gar nicht herum? Entscheidend ist, wie man streitet. Streiten kann reif, fair, konstruktiv sein, aber auch zerstörerisch, verletzend, unreif. Das Erlernen eines fairen Streitstils ist eine wichtige Voraussetzung dafür, mit Konflikten auch im beruflichen Alltag und unter Stressbedingungen sinnvoll umzugehen. Dadurch werden einerseits sinnlose Konflikte, die keinen tieferen Hintergrund haben, automatisch verringert. Andererseits kommen unvermeidbare Konflikte auf den Tisch, können ausgetragen und gelöst werden.

Herzlichst

Ihr

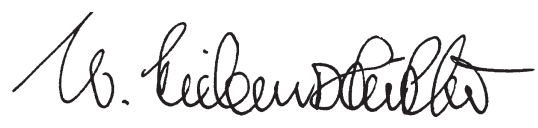

WOLFGANG SIEBENPFEIFFER,

Stuttgart, im April 2012

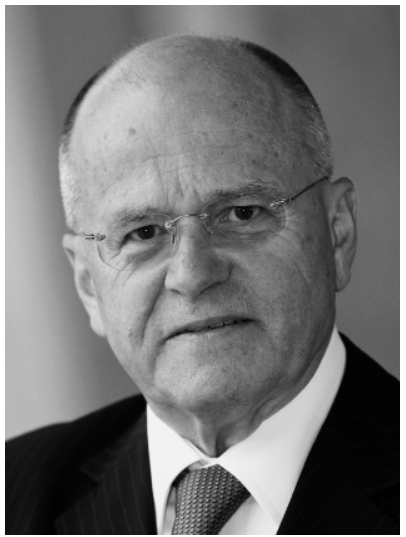

\section{Engine}

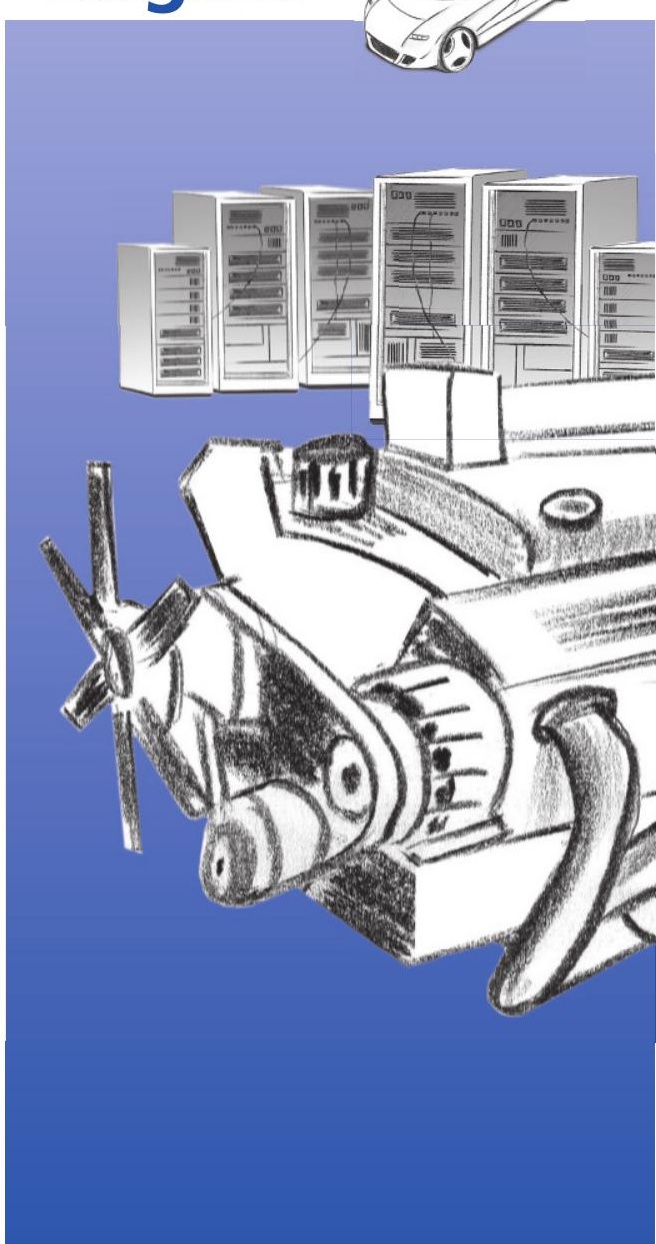

Steuergeräteentwicklung

im virtuellen Testfahrzeug

- Durchgängige Simulationsumgebung für MiL, SiL, HiL

- Zuverlässige Motormodelle mit passendem Detaillierungsgrad

- Nahtlose Integration Ihrer Modellteile

- Übersichtliche Bedienung, Datenmanagement und Auswertung

Top-Simulationsjobs Mehr erfahren und bewerben: www.tesis-dynaware.com/jobs 